\title{
Response of Partially Saturated Non-cohesive Soils
}

\author{
Waldemar Świdziński, Jacek Mierczyński, Agata Mikos \\ Institute of Hydro-Engineering, Polish Academy of Sciences, ul. Kościerska 7, 80-953 Gdańsk, Poland \\ e-mails: waldek@ibwpan.gda.pl, mier@ibwpan.gda.pl, a.mikos@ibwpan.gda.pl
}

(Received November 27, 2017; revised December 29, 2017)

\begin{abstract}
This paper analyses and discusses experimental results of undrained triaxial tests. The tests were performed on non-cohesive partially saturated soil samples subjected to monotonic and cyclic loading. The tests were aimed at determining the influence of saturation degree on soil's undrained response (shear strength, excess pore pressure generation). The saturation of samples was monitored by checking Skempton's parameter $B$. Additionally, seismic P-wave velocity measurements were carried out on samples characterized by various degrees of saturation. The tests clearly showed that liquefaction may also take place in non-cohesive soils that are not fully saturated and that the liquefaction potential of such soils strongly depends on the $B$ parameter.
\end{abstract}

Key words: partial saturation, liquefaction, pore pressure generation, triaxial conditions

\section{Introduction}

Saturated soils (pure sands and gravels, as well as sands with some fines content) subjected to shearing may liquefy. The liquefaction phenomenon can be a result of monotonic (static liquefaction) as well as cyclic loading (liquefaction, cyclic mobility), Castro (1975), Ishihara (1998), Świdziński (2006). For the liquefaction phenomenon to occur some specific conditions are needed. One of them is the initial state of soil defined by two parameters: the initial void ratio (initial density) and the corresponding mean effective stress. This definition is characteristic of non-cohesive soil, which, without additional external stresses, is incapable of retaining its structure of a set of separate grains with practically no shear strength. Only external confined stresses allow non-cohesive soils to have features of a solid, such as density, elasticity or plasticity. Determining the initial state of non-cohesive soil must therefore take into account the level of external stresses that hold the grains set in equilibrium (Świdziński 2006).

These two variables (the void ratio and the mean effective stress) define the space of possible initial states of non-cohesive soil. This space is split by the steady-state 
line (Poulos 1981), which is a boundary separating two types of soil response depending on the initial state of soil, i.e. a contractive response, when dry non-cohesive soil subjected to shearing decreases in volume and a dilative one, when the reverse phenomenon occurs, Been and Jefferies (1985). The contractive or dilative response of dry soil is directly related to the corresponding undrained reaction of such a soil when fully saturated and sheared under undrained conditions. In initially contractive saturated soil, the tendency to reduce its volume will manifest itself by the generation of excess pore pressure, regardless of the type of load (monotonic or cyclic), until the soil liquefies. Thus, the soil's susceptibility to liquefaction is closely related to its initial state (Świdziński 2005, Mierczyński 2008).

The second basic factor that determines whether the soil liquefies or not is the presence of pore water and the level of saturation. Previous experimental studies on the liquefaction phenomenon carried out by the present authors indicate that in order to liquefy soil specimens in the laboratory, it is necessary to achieve a very high level of saturation of pores with water, (Świdziński and Mierczyński 2003, 2005). For that purpose, a special technique is used aimed not only at filling soil pores with water, but also at removing the air trapped in porous space or dissolved in pore water. It consists of a few specific steps such as the replacement of the pore air in a dry sample with carbon dioxide (which much better dissolves in water), slow saturation with water and, finally, the compression of the residual gas by applying back pressure. At present, these are standard methods to obtain high saturation in saturated soil samples used in reputable geotechnical laboratories, including the Geotechnical Laboratory of the Department of Geomechanics IBW PAN.

In nature, such idealized conditions, which can be achieved in the laboratory, are relatively rare. In most practical cases, layers of saturated non-cohesive soil lie near the ground surface, often with a zone of incomplete saturation above the free water table. Such a situation occurs, for example, in tailings storage facilities (TSF) where post-flotation sediments are deposited by spigotting. Deposition of sediments in the form of a soil-water mixture causes its natural segregation resulting in the settlement of coarse fractions close to the place of discharge, while finer fractions are transported in the form of slurries towards the central part of the facility. As a result, the sediments filling the central part of the are in a loose state. Moreover, a large mass of such tailings is saturated with water, which creates ideal conditions for liquefaction. The threat of potential failure is magnified by the methodology of construction of such facilities when they are developed by the upstream method, which results in a permanent change in the mass-force system and corresponding shear stresses. An example of such a facility is the copper ore post-flotation waste disposal site KGHM POLSKA MIEDŹ S.A. "Żelazny Most”, the largest installation of this type in Europe and one of the largest in the world (Świdziński et al 2015). Studies on fully saturated tailings subjected to monotonic and cyclic loads under undrained conditions were the subject of one of the authors' work, conducted in previous years (Świdziński 2011, 2013). 
The questions then arise how partial saturation affects the undrained response of saturated soil, are there any limit values of saturation below which the non-cohesive saturated soil does not liquefy, and how to determine the soil's susceptibility to liquefaction depending on its degree of saturation.

In order to answer these questions, a series of triaxial tests on the same non-cohesive soil was conducted under similar test conditions corresponding to the contractive state of soil, but for different levels of saturation. The tests were performed on post-flotation sediment with the highest value of sand to fines ratio SFR, characterized by the smallest content of the fines fraction. During the tests, samples were subjected to both monotonic and cyclic loads. The results show that even partially saturated samples can liquefy, although the response of non-cohesive soils under undrained conditions corresponds to the reaction of such soils, but fully drained, when the saturation decreases.

Moreover, the impact of the saturation degree on the velocity of seismic waves (P-wave) was also verified, which, under natural conditions, is often used for precise identification of the fully saturated zone.

\section{Response of Partially Saturated Soil under Triaxial Compression Conditions}

\subsection{General Information}

The research was carried out on specimens of tailings from the relazny Most TSF taken as disturbed samples at a $50 \mathrm{~m}$ distance from the dam's crest. Owing to the sedimentation process, the samples were characterized by a high value of SFR $=15.67$ and a low content of the fine fraction (about 6\%), so it can be assumed that the behaviour of such a soil is very similar to that of pure sand. The basic index properties are shown in Table 1 (Świdziński 2011). The grain size distribution curve (Fig. 1) clearly shows that we are dealing with fine sand.

Table 1. Index properties of soil tested (Świdziński 2011)

\begin{tabular}{|c|c|c|c|c|c|c|c|c|}
\hline $\begin{array}{c}w_{n} \\
{[\%]}\end{array}$ & $\begin{array}{c}\rho_{s} \\
{\left[\mathrm{Mg} / \mathrm{m}^{3}\right]}\end{array}$ & $\begin{array}{c}\rho_{d_{\max }} \\
{\left[\mathrm{Mg} / \mathrm{m}^{3}\right]}\end{array}$ & $\begin{array}{c}\rho_{d_{\min }} \\
{\left[\mathrm{Mg} / \mathrm{m}^{3}\right]}\end{array}$ & $\begin{array}{c}e_{\max } \\
{[-]}\end{array}$ & $\begin{array}{c}e_{\min } \\
{[-]}\end{array}$ & $\begin{array}{c}d_{50} \\
{[\mathrm{~mm}]}\end{array}$ & $\begin{array}{c}\text { fines }<0.075 \mathrm{~mm} \\
\text { content }[\%]\end{array}$ & $\begin{array}{c}\text { SFR } \\
{[-]}\end{array}$ \\
\hline 5.83 & 2.675 & 1.63 & 1.32 & 1.026 & 0.643 & 0.157 & 5.8 & 15.67 \\
\hline
\end{tabular}

A simple estimation of the liquefaction potential is based on Tsuchida curves (PIANC, 2001, see Fig. 1). These curves define regions of possible liquefaction (b-a and $\left.\mathrm{a}^{\prime}-\mathrm{b}^{\prime}\right)$ and highly possible liquefaction (a-a'). Fig. 1 indicates that the soil tested is susceptible to liquefaction. 


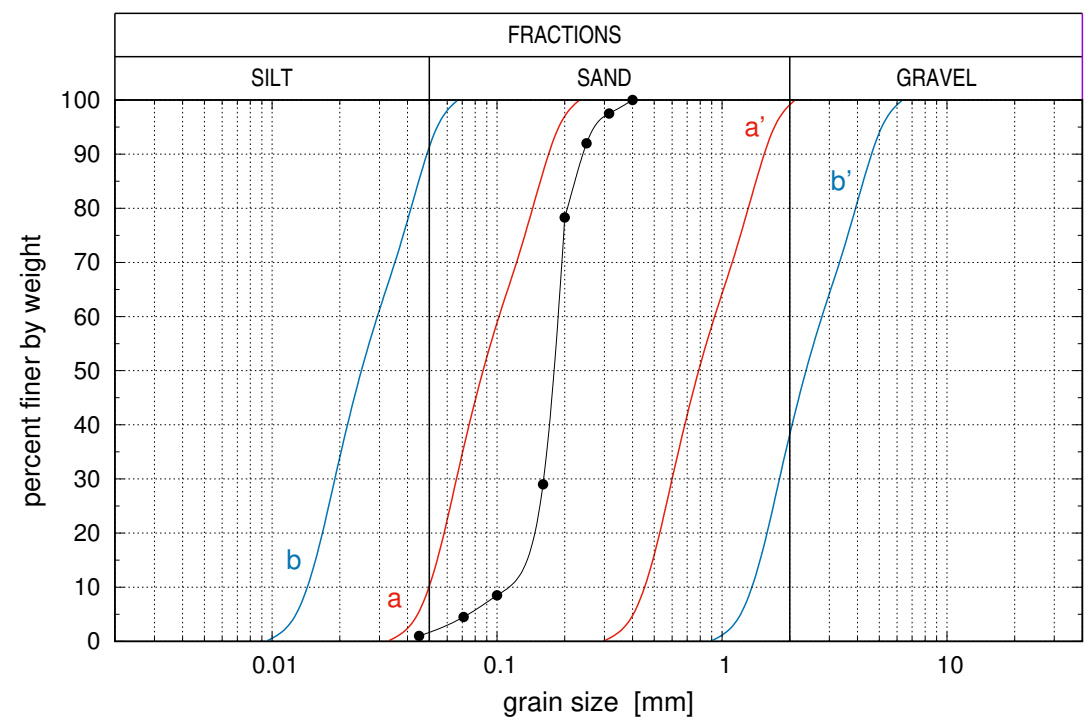

Fig. 1. Grain size distribution curve of the tailings and boundary curves proposed by Tsuchida (PIANC 2001)

\subsection{Sample Preparation}

The monotonic tests on the specimens of partially saturated tailings subjected to shearing under undrained conditions were carried out in a GDS Instruments Ltd. triaxial apparatus equipped with local displacement transducers required for full control of the initial void ratio and its changes after placing the specimen in the triaxial chamber. For this purpose, local horizontal and vertical Hall-effect transducers were installed on the sample immediately after it was formed.

The research was carried out on reconstituted samples formed by the moist tamping method (Świdziński and Mierczyński 2003, 2005). This made it possible to obtain loose samples with a homogeneous density distribution. It was extremely important to ensure a relative repeatability of the initial state of individual samples in order to maximally isolate the effect of the saturation level on test results. Therefore, sample preparation and all test stages preceding the moment of applying the deviator load were given special attention.

The sample saturation level was controlled by checking the value of Skempton's coefficient $B$, which is defined as follows (Skempton 1954):

$$
B=\frac{1}{1+\frac{n \kappa_{f}}{\kappa_{s}}}=\frac{\Delta u}{\Delta \sigma_{3}},
$$


where $n$ is porosity, $\kappa_{f}$ is the coefficient of pore fluid compressibility, $\kappa_{s}$ is the coefficient of soil skeleton compressibility, $\Delta \sigma_{3}$ is the cell pressure increment, and $\Delta u$ is the corresponding increment in pore pressure when undrained conditions are applied.

According to the first term of Eq. (1), in the case of a dry sample with pores filled with air, $\kappa_{f} / \kappa_{s}$ tends to infinity (due to the very high compressibility of air) and $B=0$, which corresponds to the degree of saturation $S_{r}=0$. On the other hand, if pores are completely filled with water without any gas components, $\kappa_{f} / \kappa_{s}$ is close to zero, so $B=1$, which corresponds to $S_{r}=1$. In general, for different saturation degrees, the $B$ value will vary between 0 and 1 .

The second term of Eq. (1) defines a convenient and practical way to determine the $B$ value by increasing the cell pressure by a predetermined value and by measuring the corresponding change in pore water pressure when undrained conditions are applied.

In order to achieve high saturation levels, the standard technique of replacing pore air with carbon dioxide was used, due to the good solubility of this gas in water compared with that of air. During this stage, both the rate of flushing and the amount of air displaced were monitored. This process took 2 to 24 hours. When the sample had been completely filled with carbon dioxide, a slow saturation process was initiated to fill all pores with water. After complete saturation and the application of the initial back pressure, the $B$ value was checked. If the result was unsatisfactory, the back pressure was increased with a simultaneous increase in the cell pressure so as to maintain a constant effective pressure, and the coefficient $B$ was checked again.

On the other hand, lower saturation was achieved by different measures, such as omitting carbon dioxide flushing, reducing back pressure, and sometimes using non-deaired water in the pressure controller that was used in the saturation process. The values of the void ratio $e_{c}$ (after consolidation) and Skempton's coefficient for soil samples subjected to monotonic loading, along with the values of the back pressure applied, are summarized in Table 2.

Table 2. Initial values of void ratio and Skempton's coefficient for samples subjected to monotonic triaxial compression

\begin{tabular}{|c|c|c|c|c|c|c|}
\hline $\begin{array}{c}\text { Test } \\
\text { no. }\end{array}$ & $\begin{array}{c}e_{c} \\
{[-]}\end{array}$ & $\begin{array}{c}I_{D} \\
{[\%]}\end{array}$ & $\begin{array}{c}B \\
{[-]}\end{array}$ & $\begin{array}{c}u_{0} \\
{[\mathrm{kPa}]}\end{array}$ & $\begin{array}{c}\mathrm{CO}_{2} \\
\text { flushing }\end{array}$ & $\begin{array}{c}\text { water } \\
\text { deaeration }\end{array}$ \\
\hline $\mathrm{m} 1$ & 0.89 & 36 & 0.93 & 300 & yes & yes \\
\hline $\mathrm{m} 2$ & 0.87 & 41 & 0.92 & 200 & yes & yes \\
\hline $\mathrm{m} 3$ & 0.86 & 43 & 0.84 & 100 & yes & yes \\
\hline $\mathrm{m} 4$ & 0.84 & 49 & 0.55 & 100 & no & yes \\
\hline $\mathrm{m} 5$ & 0.84 & 49 & 0.74 & 150 & no & no \\
\hline $\mathrm{m} 7 *$ & 0.85 & 46 & 0.39 & 50 & no & no \\
\hline $\mathrm{m} 8$ & 0.89 & 36 & 0.29 & 10 & no & no \\
\hline
\end{tabular}

* closed water outflow during saturation

All samples were isotropically consolidated to the same effective stress of $p^{\prime}=$ $400 \mathrm{kPa}$ and subsequently subjected to triaxial compression at a constant cell pressure 
and sheared at a controlled deformation rate of $10 \% / \mathrm{h}$. The test was continued up to a vertical strain of more than $25 \%$ until the steady state of deformation was reached.

Fig. 2 shows the initial states of all samples (also those subjected to cyclic loading) in the $\left(e_{c}, p^{\prime}\right)$ space and the steady-state of deformation line determined previously from triaxial tests conducted on the same soil subjected to undrained triaxial compression, but with a very high level of saturation $\left(B_{\min }=0.97\right.$, Świdziński 2011). All the points representing the initial states of samples which were subsequently subjected to monotonic loading are located above the steady-state line on the contractive side.

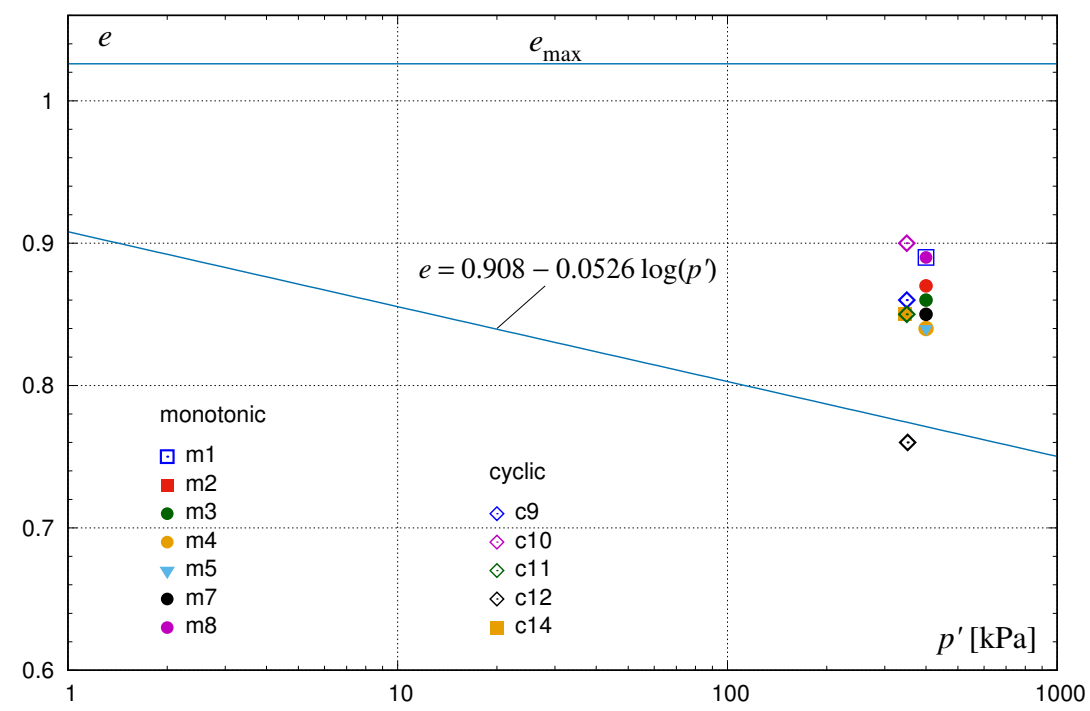

Fig. 2. Initial states of samples

As shown in Table 2, the average initial void ratio of monotonically loaded samples was 0.865 with a small standard deviation of 0.02 , which corresponds to a medium dense soil $\left(I_{D}=42 \%\right)$. The initial states of the samples were very similar, which, in case of non-cohesive soil, is not easy to achieve. Note that the control of the density of reconstituted samples is very difficult. The difficulties start from the phase of sample preparation in the rubber membrane and continue throughout the subsequent stages preceding the application of deviatoric loading. During the closing of the top of the sample, the installation of local displacement transducers, the saturation process and finally consolidation, volumetric changes are recorded and included in the calculation of the initial void ratio thanks to the accurate local measurement of horizontal and vertical deformations. Moreover, in order to avoid an uncontrolled deformation of the sample during the installation of local transducers, a slight negative pressure (up to $20 \mathrm{kPa}$ ) is introduced into the sample. All these procedures require a lot of precision and experience from the researcher. 
Table 2 also shows that, due to different techniques, the level of pore saturation with water was different, ranging from $B=0.29$ to $B=0.93$.

\subsection{Response of Partially Saturated Sediments Subjected to Monotonic Undrained Triaxial Compression}

Fig. 3 shows the stress paths (in the space of the stress deviator $q=\sigma_{1}-\sigma_{3}$ and the mean effective pressure $\left.p^{\prime}=\left(\sigma_{1}+2 \sigma_{3}\right) / 3\right)$ for all monotonically loaded samples. Moreover, a stress path corresponding to the typical response of dry or fully drained soil is shown as well (solid green line). Figs. 4 and 5 show changes in the deviator stress and pore pressure, respectively, againsts vertical strain. Since the tests were carried out at a constant vertical strain rate of $8 \mathrm{~mm} / \mathrm{h}$, deformation in this case can be regarded as a measure of time.

Table 3 lists the values of selected parameters, as defined in Figs. 4 and 5. For better readability, the tests are listed from the highest to the lowest $B$ value.

The results presented in Figs. 3-5 reveal a regular response of all samples, except sample $\mathrm{m} 7$, in which an unexpected drop in deviator occurred (black colour). This was due to a different failure mechanism after the maximum deviator was reached. The difference is clearly visible in the photographs of deformed samples (Fig. 6) showing a typical deformation characteristic of most samples (Fig. 6a) and another type of failure in sample $\mathrm{m} 7$ (Fig. 6b), which resembles a deformation of a high-density non-cohesive sample.

Table 3. Values of selected parameters, as defined in Figs. 4 and 5

\begin{tabular}{|c|c|c|c|c|c|c|c|}
\hline $\begin{array}{l}\text { Test } \\
\text { No. }\end{array}$ & $\begin{array}{c}B \\
{[-]} \\
\end{array}$ & $\begin{array}{c}q_{\max } \\
{[\mathrm{kPa}]}\end{array}$ & $\begin{array}{c}\varepsilon_{1 \max } \\
{[\%]}\end{array}$ & $\begin{array}{c}q_{\min } \\
{[\mathrm{kPa}]}\end{array}$ & $\begin{array}{c}\Delta q=q_{\max }-q_{\min } \\
{[\mathrm{kPa}]}\end{array}$ & $\begin{array}{c}u_{\max } \\
{[\mathrm{kPa}]}\end{array}$ & $\begin{array}{c}u_{\max } / p_{c}^{\prime} \\
{[-]}\end{array}$ \\
\hline $\mathrm{m} 1$ & 0.93 & 176.4 & $1.05^{*}$ & 16.9 & 155.5 & 398.4 & 0.996 \\
\hline $\mathrm{m} 3$ & 0.92 & 154.0 & 1.11 & 7.4 & 146.6 & 396.4 & 0.991 \\
\hline $\mathrm{m} 2$ & 0.84 & 223.4 & 1.46 & 45.0 & 178.4 & 385.7 & 0.964 \\
\hline $\mathrm{m} 5$ & 0.74 & 304.3 & 2.59 & 155.4 & 148.9 & 332.5 & 0.831 \\
\hline $\mathrm{m} 4$ & 0.55 & 389.7 & 4.13 & 303.9 & 85.8 & 273.3 & 0.683 \\
\hline $\mathrm{m} 7$ & 0.39 & 566.1 & 7.68 & 454.7 & $112.0^{* *}$ & 143.1 & 0.358 \\
\hline $\mathrm{m} 8$ & 0.29 & 648.9 & 15.68 & 614.6 & 34.3 & 121.2 & 0.303 \\
\hline
\end{tabular}

Based on the data shown in Figs. 3-5, the following conclusions can be drawn:

- excess pore pressure was generated in all samples, although to various levels, cf.

Fig. 5 and Table 3,

- all samples reached the steady-state of deformation, cf. Fig. 4, 


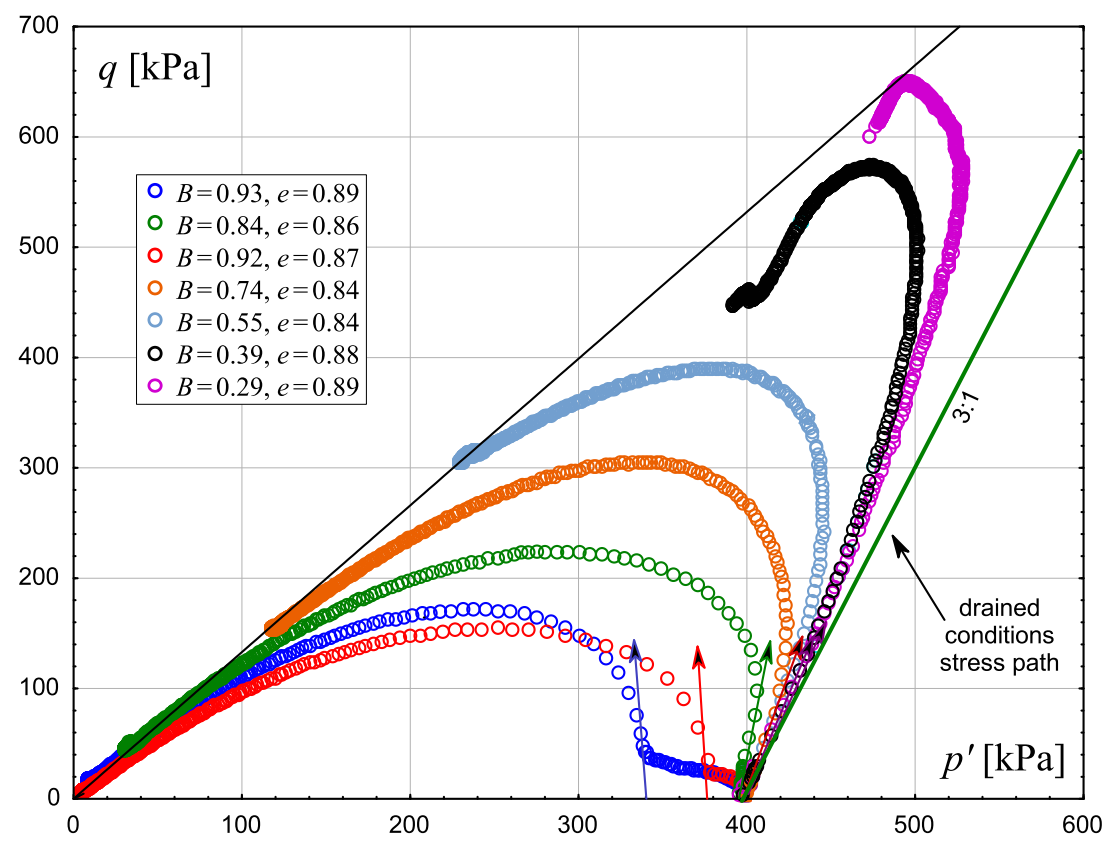

Fig. 3. Stress paths representing the response of partially saturated tailings under undrained conditions at different levels of saturation

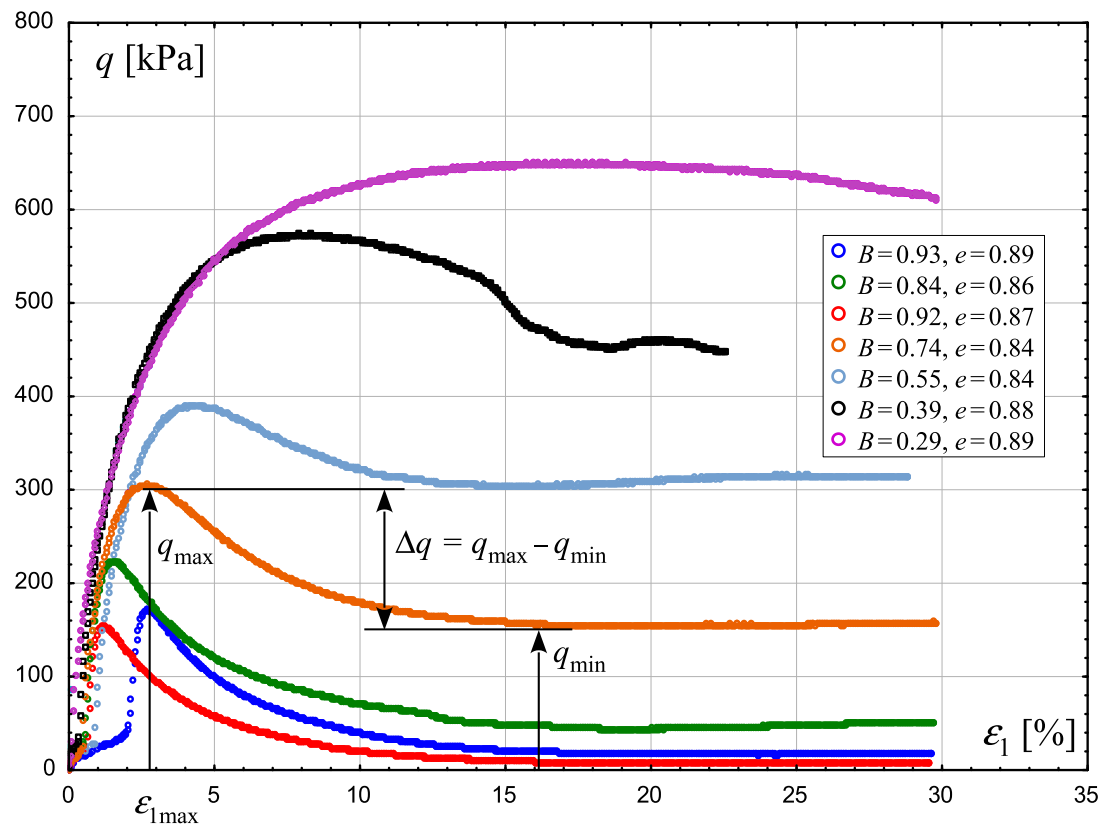

Fig. 4. Response of partially saturated tailings under undrained conditions at different levels of saturation: deviator stress vs. vertical strain 


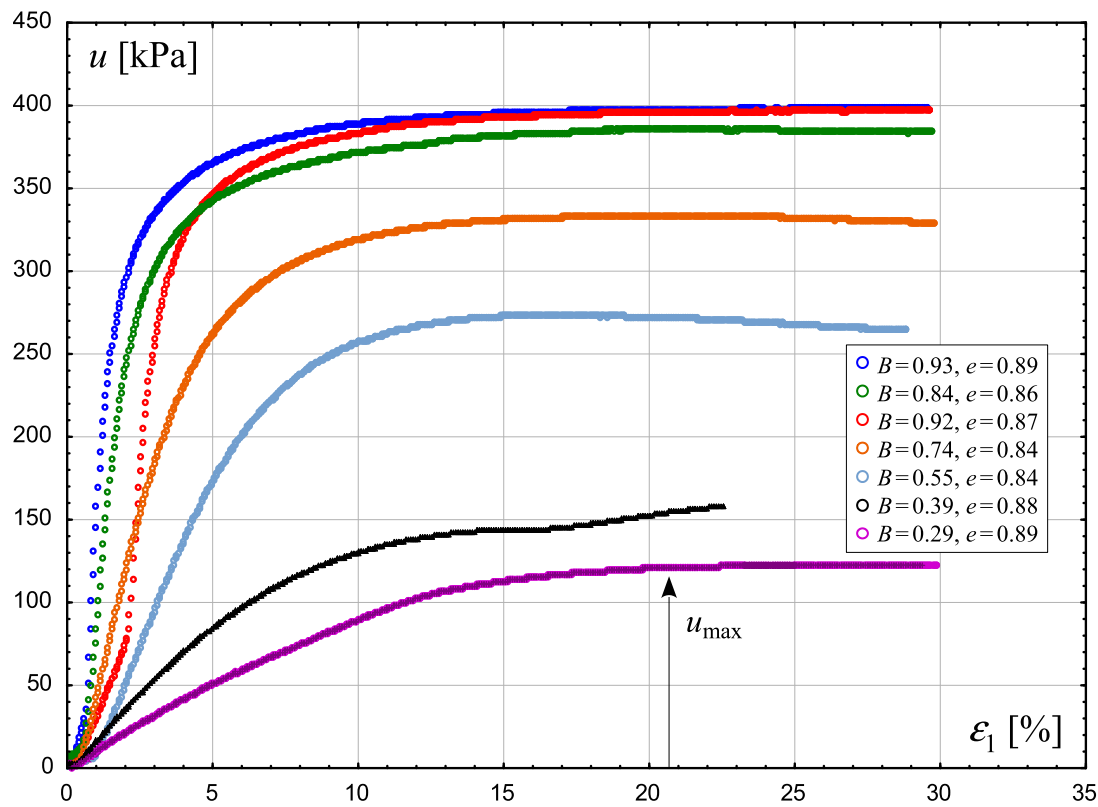

Fig. 5. Response of partially saturated tailings under undrained conditions at different levels of saturation: excess pore water pressure vs. vertical strain

a)

b)

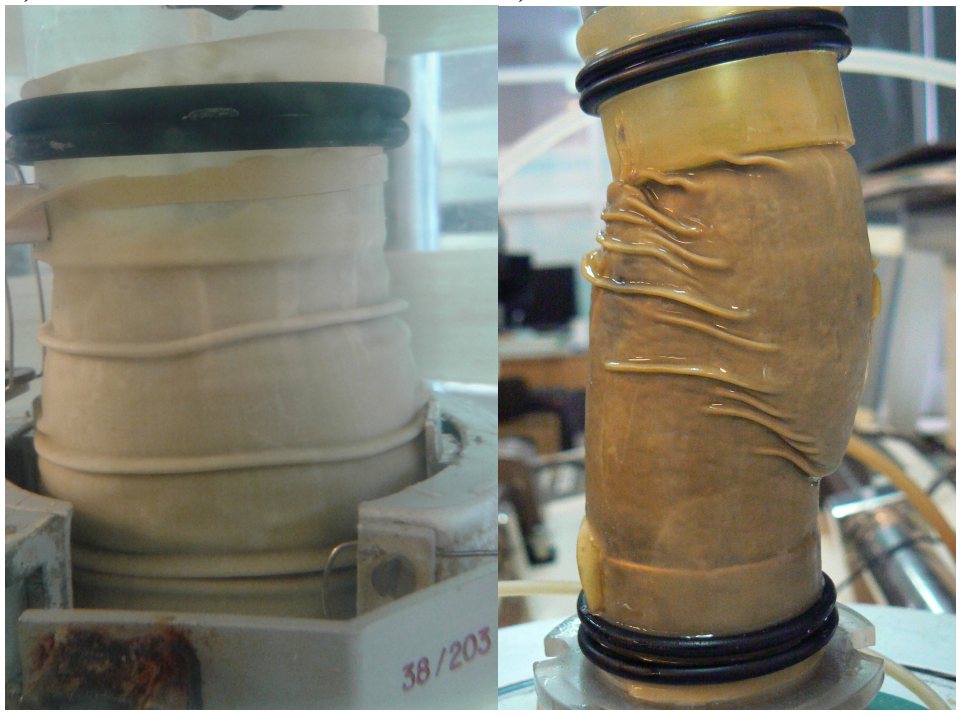

Fig. 6. Different types of failure: a) samples $m 1-m 6$ and $m 8$, b) sample $m 7$ 
- only some of the samples showed a typical contractive response manifested in a significant reduction in the stress deviator after it had reached its maximum; low saturation samples responded as those under fully drained conditions,

- one common instability line could not be identified for samples with different levels of saturation,

- with decreasing saturation (expressed by the $B$ coefficient), a higher maximum value of the stress deviator was reached, and, for greater vertical deformation, the post-peak reduction in deviator stress was smaller and the excess pore pressure was lower,

- the slope of the tangent to the stress path in the first stage of shearing (as soon as the deviator had increased above zero) varied depending on the level of saturation; with decreasing saturation, the stress path became closer to the path corresponding to drained conditions.

Fig. 7 shows the relations between the $B$ value and the maximum pore pressure $u_{\max }$ and the corresponding effective horizontal stress $\sigma_{3}^{\prime}$ normalized by the effective consolidation stress $p_{c}^{\prime}$, cf. Fig. 5 and Table 3 . The limit values of $B$ and the corresponding pore pressure and effective stress resulting from the physics of the problem were added to the graph (dry sample: $B=0 \rightarrow u_{\max } / p_{c}^{\prime}=0 \rightarrow \sigma_{3}^{\prime} / p_{c}^{\prime}=1$, fully saturated sample: $\left.B=1 \rightarrow u_{\max } / p_{c}^{\prime}=1 \rightarrow \sigma_{3}^{\prime} / p_{c}^{\prime}=0\right)$.
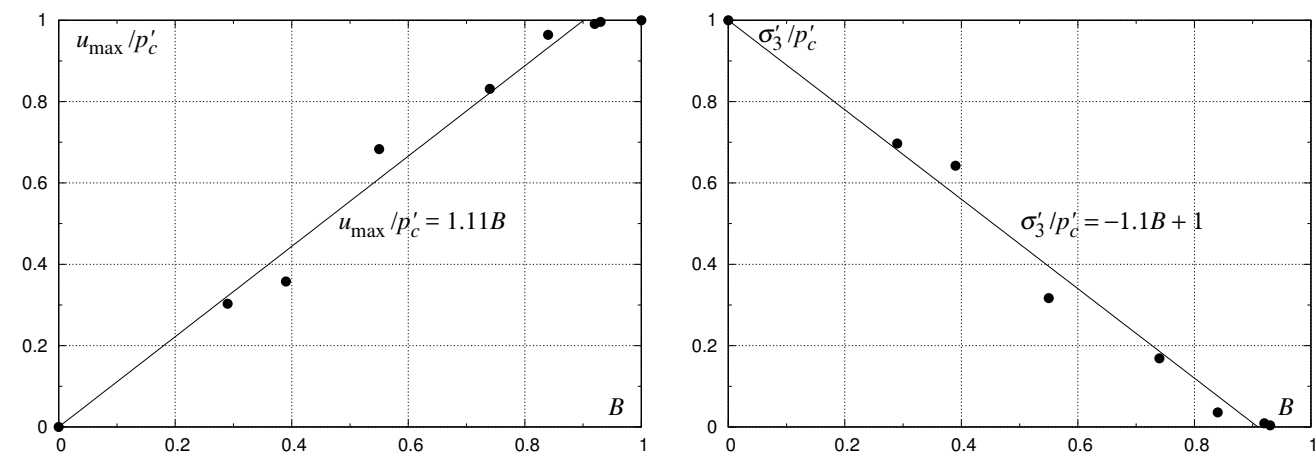

Fig. 7. Changes of the maximum pore pressure $u_{\max }$ and the corresponding effective horizontal stress $\sigma_{3}^{\prime}$ normalized by the effective consolidation stress $p_{c}^{\prime}$

Linear functions were chosen as the first approximation of experimental results, although the arrangement of experimental points, especially for high $B$ values, suggests that a nonlinear function could be applied, which should also satisfy the above conditions for the limit values of this coefficient. The first approximation is used only to show apparent trends in both relations.

The results presented in Fig. 7 show that the lower level of sample saturation, expressed by the low value of $B$, corresponds to the lower value of excess pore pressure generated. The stress paths shown in Fig. 3 and the results from Fig. 7 lead to the conclusion that liquefaction occurred for $B=0.55$ and higher. In these samples, 
the tendency for the maximum pore pressure $u_{\max }$ to increase along with the sample saturation level is evident. For $B$ values greater than 0.8 , the excess pore pressure generated is close to the external pressure, which means that the corresponding effective pressure is very low, and so is the residual shear strength of liquefied soil, cf. Table 3 and Fig. 4. For lower $B$ values, but still higher than 0.5 , liquefaction also occurs, but the residual shear strength is much higher.

This is well illustrated in Fig. 8, which shows the dependence of the maximum and minimum values of the deviator stress on the coefficient $B$ (see also Figs. 3 and 4 ). For $B$ values close to 1 (full saturation), the minimum and maximum values of the stress deviator are very low, showing the low shear strength of such soil and its high susceptibility to liquefaction. For these $B$ values, the difference between the maximum and the minimum deviator $\Delta q$, which identifies its reduction after reaching the instability line, is the greatest. With decreasing $B$, these differences become smaller (see Table 3 and the different slopes of lines presented in Fig. 8).

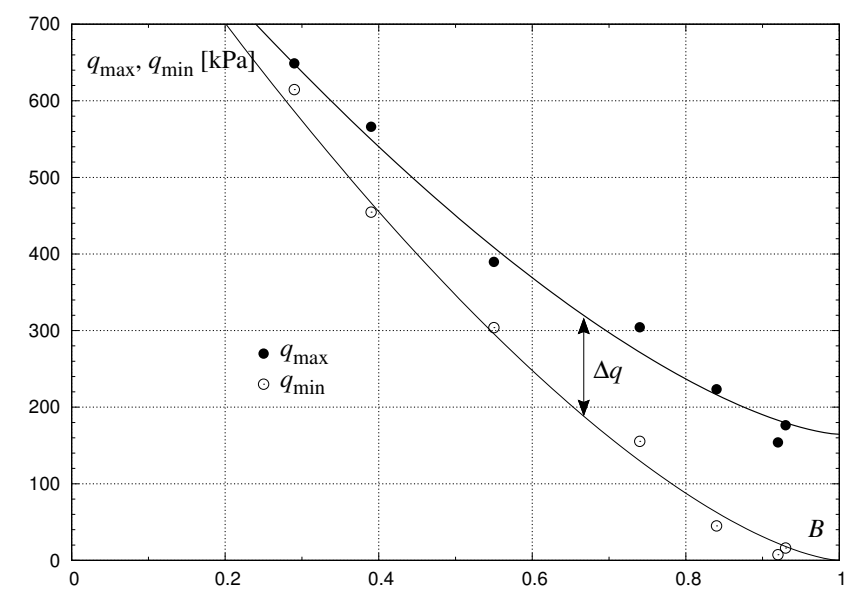

Fig. 8. The maximum and minimum values of the deviator stress vs. $B$

Fig. 9 shows the impact of saturation on the value of vertical strain $\varepsilon_{1 \max }$ corresponding to the point at which the stress path reaches the maximum value of the deviator stress $q_{\max }$ (cf. Fig. 4). It may be seen that the higher $B$ values correspond to the lower values of the vertical strain, at which the stress deviator is the highest and vice versa. This is characteristic of fully saturated soils when maximum deviator is reached at relatively small deformations (at instability line) of the order of $1 \%$ and afterwards shear strength drops to the residual value (Świdziński 2006). For low $B$ values corresponding to drained conditions, this deformation is much larger.

When addressing the problem of the instability line, it should be noted that its shape is not the same as for fully saturated samples, for which the points corresponding to mean effective and maximum values of deviator stresses lie along a straight 


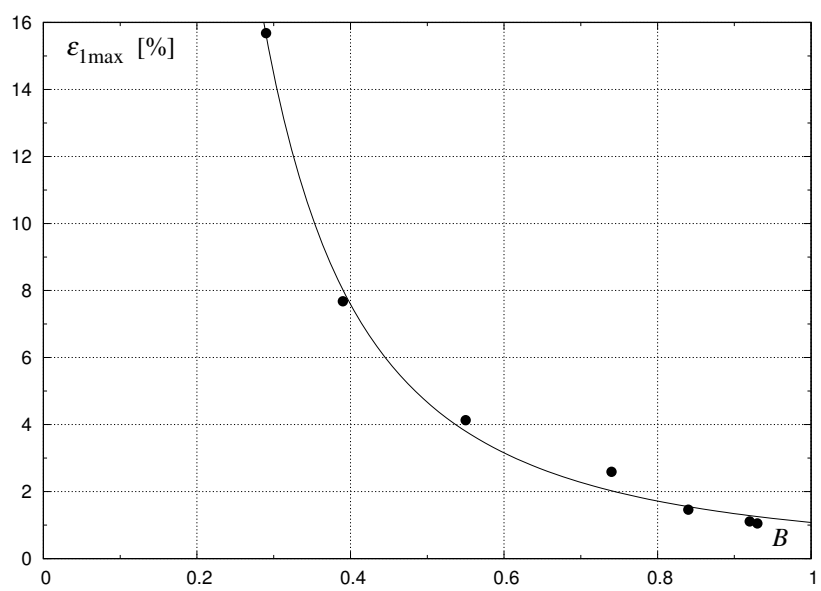

Fig. 9. Vertical strain corresponding to the maximum deviator stress vs. $B$, cf. Fig. 4

line (eg. Lipiński 2000, Świdziński 2006). It should also be emphasized that, except for the sample with $B=0.29$, the maximum values of the deviator lie below the Coulomb-Mohr failure line.

Moreover, the initial slope of the tangent to the stress paths changes with decreasing saturation level, so that, for low saturation, the stress paths approach the path corresponding to full drainage conditions $(B=0)$, for which the slope of the tangent in the $\left(q, p^{\prime}\right)$ space is 3:1 (see Fig. 3). In the case of $B=1$ (full saturation), it is helpful to use an equation describing the pore pressure change resulting from the monotonic load (Skempton 1954):

$$
\Delta u=B\left[\Delta \sigma_{3}+A \Delta q\right],
$$

where $\sigma_{3}$ is the triaxial cell pressure, and $A$ is the coefficient corresponding to the pore pressure increase due to deviatoric load. In the case of isotropic, elastic soil, the coefficient $A=1 / 3$, cf. Skempton (1954). In this case, Eq. (2) is reduced to a simpler form:

$$
\Delta u=\Delta \sigma_{3}+\frac{1}{3} \Delta q
$$

Assuming a triaxial test with a constant cell pressure, it follows that $\Delta \sigma_{3}=0$. Also:

$$
p=\frac{1}{3}\left(\sigma_{1}+2 \sigma_{3}\right) \quad \text { and } \quad q=\sigma_{1}-\sigma_{3}, \quad \text { so } \quad p=\sigma_{3}+\frac{1}{3} q .
$$

According to Terzaghi's principle, the mean effective stress $p^{\prime}$ is the difference between the total stress $p$ and the pore pressure $u$ :

$$
p^{\prime}=p-u \quad \text { or } \quad \Delta p^{\prime}=\Delta p-\Delta u .
$$


Substituting Eqs. (2) and (4) into Eq. (5) and remembering that $\Delta \sigma_{3}=0$, we obtain

$$
\Delta p^{\prime}=\Delta \sigma_{3}+\frac{1}{3} q-\Delta u=0 .
$$

This means that for fully saturated soil subjected to shearing, the initial stress path corresponds to pure shearing $\left(p^{\prime}=\right.$ const), so the initial part of this path is perpendicular to the horizontal axis in the $\left(q, p^{\prime}\right)$ stress space. After the initial excess pore pressure has been generated, the stress path deflects to the left towards the failure envelope, unlike for fully drained conditions, under which the stress path (at a constant cell pressure) follows right along a straight line with a 3:1 slope. The conditions described above define the limits of the stress path inclination for $B$ values changing from 0 to 1 .

\subsection{Response of Saturated Tailings Subjected to Undrained Cyclic Triaxial Compression}

The tests were carried out in the same triaxial apparatus as in the case of monotonic loads. The samples were subjected to a constant cell pressure and sinusoidal cyclic loading with an assumed stress amplitude:

$$
q=q_{0}+\Delta \sigma_{1} \sin \omega t
$$

where $\omega=2 \pi f$, and $\Delta \sigma_{1}$ is the cyclic vertical stress amplitude. Cyclic loading was performed at a relatively low frequency of about $0.017 \mathrm{~Hz}(1 \mathrm{cycle} / \mathrm{min})$.

Similarly as in the case of monotonic studies, the effect of sample saturation was maximally isolated, while maintaining the remaining parameters of each test constant. This was done by preparing samples with a similar void ratio and keeping load conditions constant. In the case of the first parameter, the void ratio was lower for only one sample. Each sample was anisotropically consolidated to the stress state determined by the mean effective pressure $p_{0}^{\prime} \approx 350 \mathrm{kPa}$ and $q_{0} \approx 200 \mathrm{kPa}$, after which undrained cyclic loading with a fixed stress amplitude of $\Delta q \approx 30 \mathrm{kPa}$ was applied.

The variable saturation level expressed by Skempton's coefficient was controlled mainly by the back pressure. As before, high $B$ values were obtained by replacing air with carbon dioxide, slow saturation with water and the application of high back pressure $u_{0}$.

The basic parameters of the tests are summarized in Table 4. The table also provides information on the sample response. For samples that liquefied, the number of cycles at which liquefaction occurred is given.

Fig. 10 shows a typical stress path of the soil subjected to undrained cyclic triaxial shear for $B=0.99$. The results presented in Fig. 10 show that the sample liquefied after about 20 loading cycles - see Fig. 11, where the vertical deformation and excess pore pressure are shown against the number of loading cycles. It should be recalled 


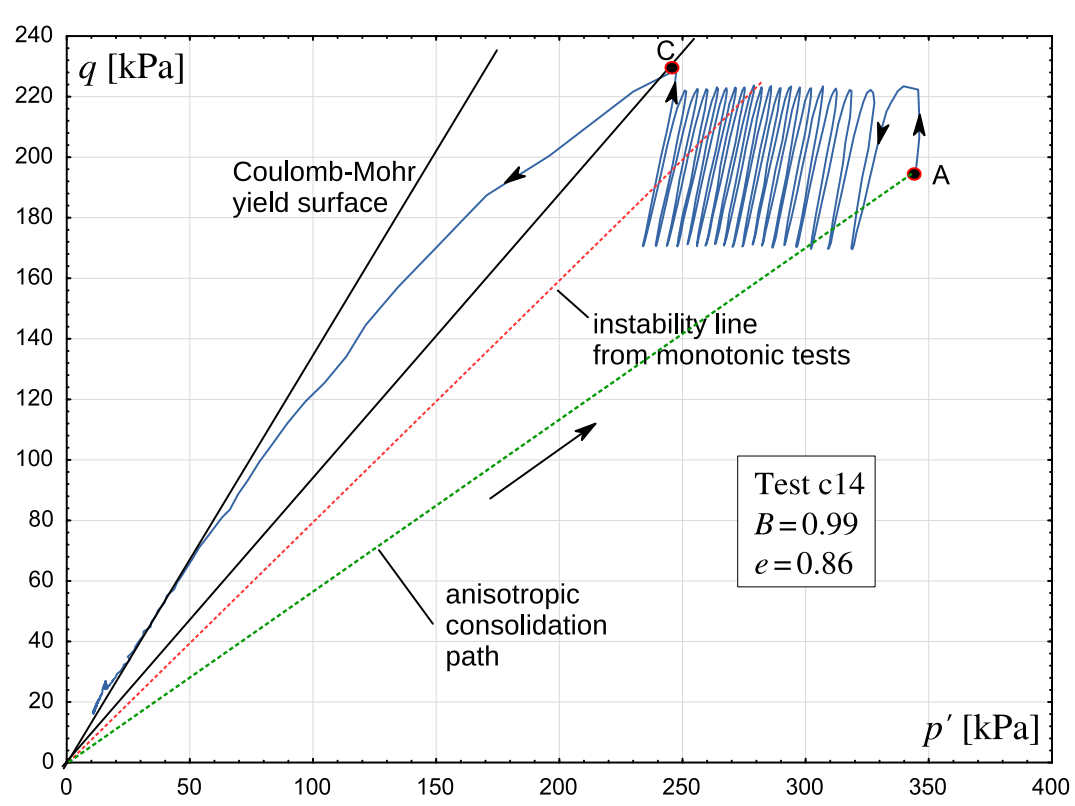

Fig. 10. Typical response of a highly saturated, cyclically loaded sample

that under undrained conditions, the vertical deformation is directly related to the deviatoric strain, Świdziński (2006):

$$
\varepsilon_{1}=\frac{3}{2} \varepsilon_{q}
$$

Liquefaction occurred (at point $\mathrm{C}$ ) as a result of a rapid increase in pore pressure (cf. Fig. 11b) when the stress path reached the instability line (Fig. 10). It should be noted that this line is very different from the monotonic instability line, which confirms earlier results (Świdziński and Mierczyński 2015).

As can be seen in Table 4, only one more sample with a similar $B$ value of 0.96 liquefied, whereas in the other samples, the excess pore pressure was insufficient to cause liquefaction, even after a large number of loading cycles.

The results of all cyclic shear tests are shown in Fig. 12 in the form of excess pore pressure against the number of loading cycles.

Table 4. Summary of the initial void ratio and Skempton's coefficient for cyclic triaxial compression test samples

\begin{tabular}{|c|c|c|c|c|c|c|}
\hline No. & $\begin{array}{c}e_{c} \\
{[-]}\end{array}$ & $\begin{array}{c}I_{D} \\
{[\%]}\end{array}$ & $\begin{array}{c}B \\
{[-]}\end{array}$ & $\begin{array}{c}u \\
{[\mathrm{kPa}]}\end{array}$ & $\begin{array}{c}\mathrm{CO}_{2} \\
\text { flushing }\end{array}$ & $N_{L}$ \\
\hline c9 & 0.86 & 43 & 0.96 & 500 & yes & 20 \\
\hline c10 & 0.90 & 33 & 0.70 & 300 & no & - \\
\hline c11 & 0.85 & 46 & 0.91 & 200 & yes & - \\
\hline c12 & 0.76 & 69 & 0.94 & 600 & yes & - \\
\hline c14 & 0.85 & 46 & 0.99 & 600 & yes & 27 \\
\hline
\end{tabular}




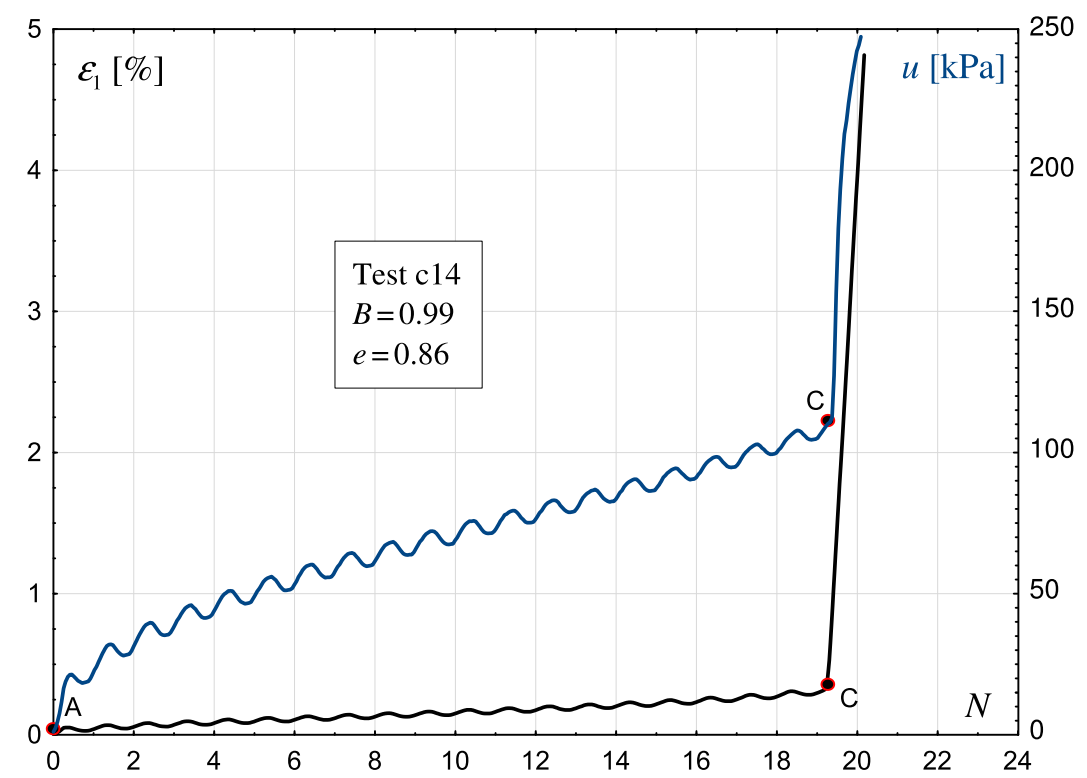

Fig. 11. Vertical deformation and excess pore pressure vs. number of load cycles

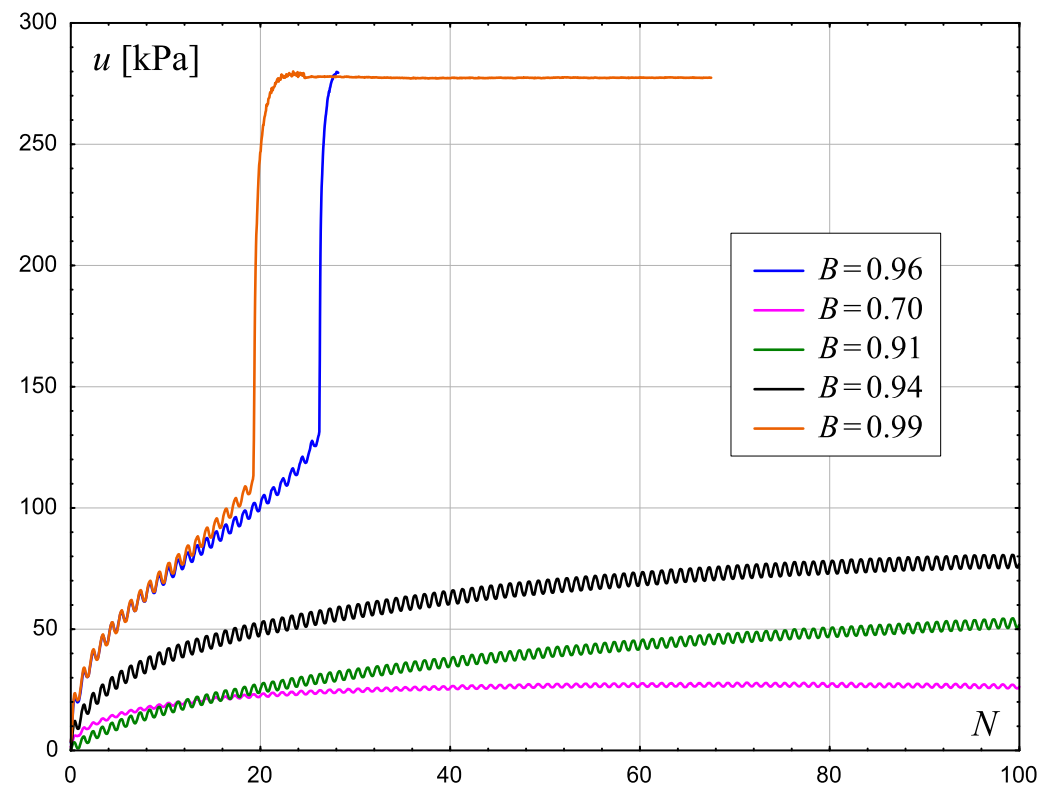

Fig. 12. Pore pressure changes for all cyclic tests 
The data shown in Fig. 12 suggest that the limit value of $B$ necessary to liquefy a sample is about 0.95 - below this limit liquefaction is not possible. Moreover, there are clear tendencies showing that, with increasing $B$ value, the number of loading cycles to liquefaction decreases (for $B>0.95$ ) and higher excess pore pressure is generated (for $B<0.95$ ). The limit $B$ value, above which cyclically loaded soil can liquefy, is much higher than in the case of static liquefaction, which occurred for $B>0.5$. However, the problem of determining the limit of soil saturation requires further research which should incorporate different values of cyclic vertical stress amplitude.

\section{Influence of the Degree of Saturation on the Velocity of the Seismic Wave}

Normally, measurements of seismic wave velocities are used to evaluate the elastic parameters of soil. The term "seismic waves" is understood as low-amplitude oscillations generated in the soil skeleton as a result of a wave transition caused by external factors. Vibrations generated at one point of the medium are progressively transmitted by individual particles through their contact surfaces, (Świdziński and Mierczyński 2010). The results of experiments show that seismic waves generated in a soil medium cause very small strains of the order of $10^{-6}$, so the response of soil within the range of such small deformations can be treated as purely elastic.

Seismic waves can propagate in solids in two different forms, and therefore two basic types of waves are distinguished:

- shear waves (S type), also called transverse waves, causing particle oscillations in a direction perpendicular to the direction of wave propagation,

- pressure waves (P type), also called longitudinal or volumetric waves, causing particle oscillations along the direction of wave propagation.

According to the theory of wave propagation in an isotropic homogeneous elastic medium, the propagation velocity of $\mathrm{S}$ and $\mathrm{P}$ waves depends on the stiffness of the material and its density:

$$
v_{s}=\sqrt{\frac{G_{\max }}{\rho}}, \quad v_{p}=\sqrt{\frac{M}{\rho}} ;
$$

where $v_{s}$ and $v_{p}$ are propagation velocities of shear and pressure waves, respectively, $G_{\max }$ is the maximum Kirchhoff's modulus of the medium, $M$ is the constrained modulus, and $\rho$ is the bulk density of the medium.

There are several factors that affect the wave propagation velocity in a soil medium. According to Lipiński (2013), the most important are physical properties (type of soil, shape and size of grains, soil fabric, mineral composition), level of effective stresses, void ratio, plasticity index, moisture content and temperature.

In the case of shear waves, which are transmitted only by the soil skeleton, the presence of pore water and saturation does not influence the propagation velocity of 
this type of waves (water does not transfer the shear stress). The reverse situation occurs in the case of pressure waves, the propagation of which depends on the presence of pore water.

Laboratory measurements of the velocity of seismic waves in a soil medium are commonly performed by piezoelectric sensors mounted on a triaxial apparatus. The design of these ceramic sensors utilizes the piezoelectric phenomenon, as a result of which these sensors either deform under the applied voltage, generating a pulse in the form of a wave, or, when deformed as a result of receiving a pulse of such a wave, they produce appropriate voltage (Świdziński and Mierczyński 2010).

The study on the effect of soil saturation on seismic wave velocity was carried out in a triaxial apparatus (manufactured by ENEL-Hydro) equipped with piezoelectric sensors. The soil tested was the same as the one used in undrained monotonic and cyclic tests. Since water does not impact the shear wave velocity, only the pressure wave velocity was investigated. Details of seismic wave velocity measurements by piezoelectric sensors in a soil medium can be found e.g. in Świdziński and Mierczyński (2010).

A medium dense soil sample was saturated, and the level of saturation was measured by checking Skempton's coefficient $B$. A pressure wave was transmitted from the bottom to the top of the sample, and the time of its passage was recorded. The tests were carried out at a constant effective stress $p_{c}^{\prime}=30 \mathrm{kPa}$.

Sample records of received $\mathrm{P}$-waves for three different $B$ values are shown in Fig. 13, while Table 5 and Fig. 14 summarize the results of all studies in the form of the pressure wave velocity dependence on $B$ values. The results shown include the limit values of the $B$ coefficient and the corresponding values of the P-wave velocity. In fully saturated soil $(B=1)$ the velocity of the seismic wave in water is $v_{p}=1450 \mathrm{~m} / \mathrm{s}$ (measured at $15^{\circ} \mathrm{C}$ ).

It can be seen from Table 5 and Fig. 14 that there is a clear correlation between the pressure wave velocity and saturation, which is quite obvious: the higher the level of saturation, the higher the velocity.

The velocity of seismic wave propagation in a soil medium can be used to assess the state of soil under natural conditions. Fig. 15 shows sample results of measurements of shear and pressure wave velocities in the tailings mass at the Żelazny Most TSF (Świdziński 2013). They were obtained by cross-hole tests measuring the wave

Table 5. P-wave velocity measurements according to degree of saturation

\begin{tabular}{|c|c|c|c|c|}
\hline No. & $u_{0}[\mathrm{kPa}]$ & $B$ & $t[\mu \mathrm{s}]$ & $v_{p}[\mathrm{~m} / \mathrm{s}]$ \\
\hline 1 & 50 & $0.1-0.2$ & 180 & 767 \\
\hline 2 & 100 & 0.47 & 162 & 852 \\
\hline 3 & 200 & 0.87 & 124 & 1114 \\
\hline 4 & 350 & 0.973 & 121 & 1142 \\
\hline 5 & 50 & 0.598 & 126 & 1096 \\
\hline
\end{tabular}




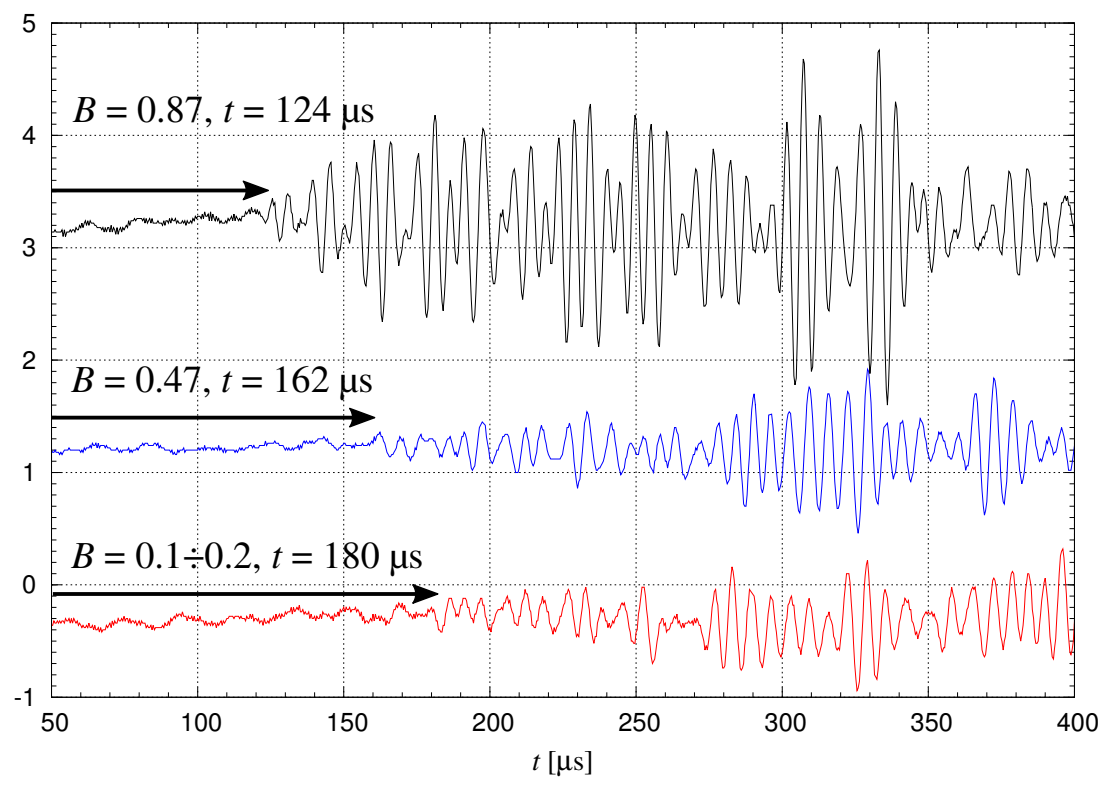

Fig. 13. Sample records of received $P$-wave signals in the soil sample examined

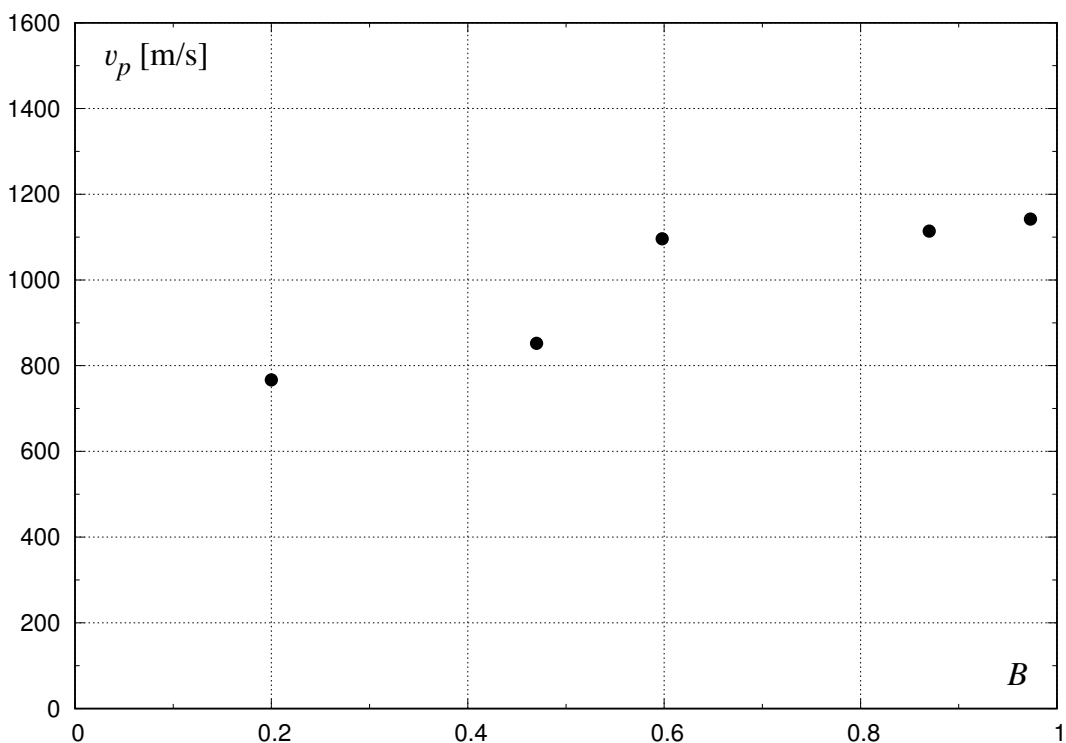

Fig. 14. Dependence of P-wave velocity on saturation expressed by Skempton's coefficient $B$ 
velocity between pairs of boreholes, in which the signal source and receiver were placed at corresponding depths.

Fig. 15 shows that the shear wave velocity increases almost linearly with depth from about $170 \mathrm{~m} / \mathrm{s}$ on the surface to about $350 \mathrm{~m} / \mathrm{s}$ at a depth of $40 \mathrm{~m}$ (strongly dependent on the mean effective pressure). The pressure wave velocity varies from about $250 \mathrm{~m} / \mathrm{s}$ at the surface to about $800 \mathrm{~m} / \mathrm{s}$ at a depth of $20 \mathrm{~m}$, and one meter below rises rapidly to $1600 \mathrm{~m} / \mathrm{s}$ and remains constant down to a depth of $40 \mathrm{~m}$. It follows that the fully saturated zone starts at a depth of about $21 \mathrm{~m}$, whereas the zone of incomplete saturation extends about $7 \mathrm{~m}$ above that depth. This is confirmed by the results of laboratory tests shown in Fig. 14. It should be noted that only one type of soil with the highest sand content was tested in the laboratory, whereas in situ tests were carried out on much finer deposits, and, as described at the beginning of this section, wave propagation depends, among other things, on the granulometric composition of soil.
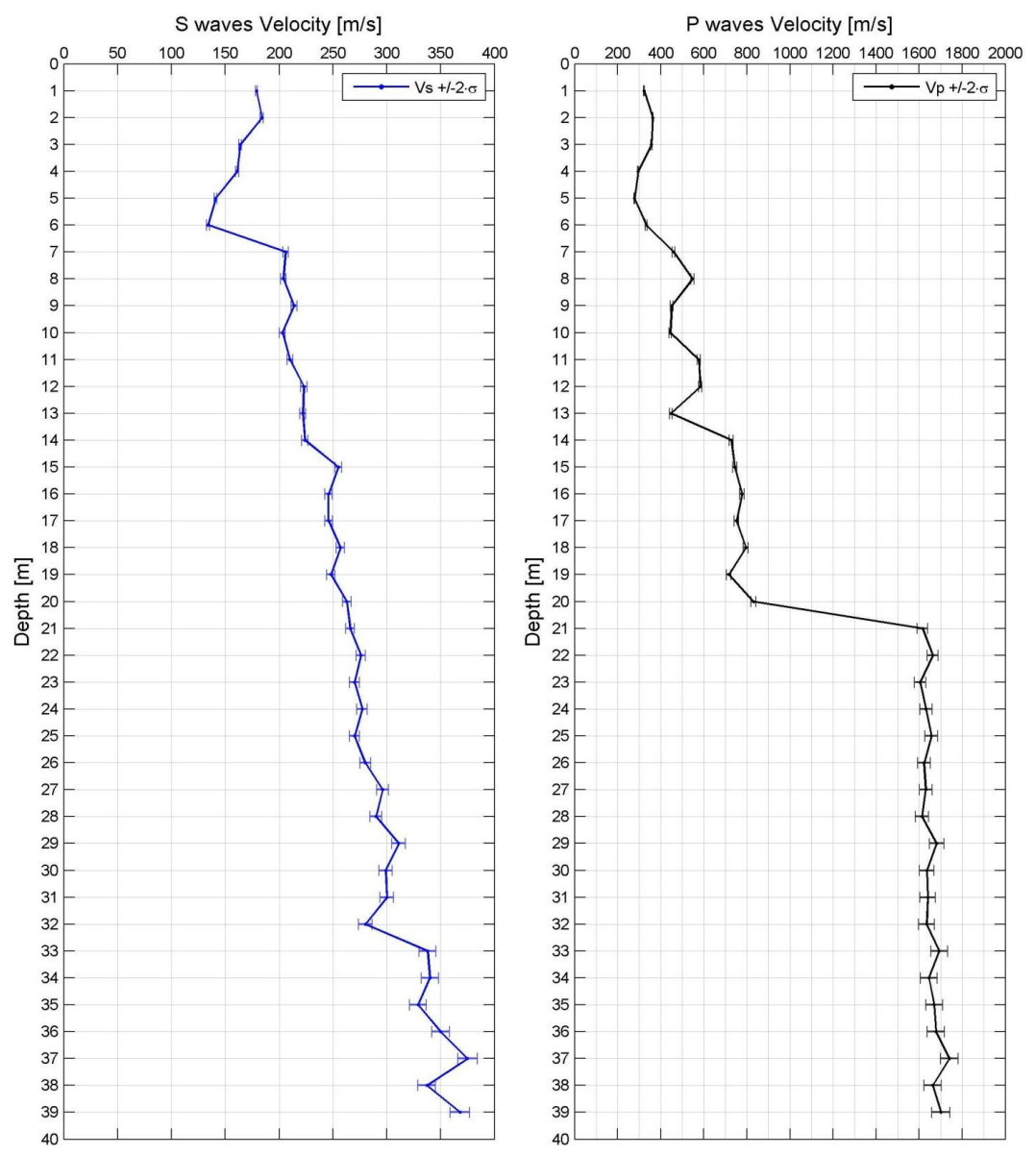

Fig. 15. Typical results of seismic wave velocity measurement in the Żelazny Most TSF 


\section{Summary}

The results of investigations of partially saturated soils under undrained conditions indicate that such soils can also liquefy. This is an important outcome from the practical point of view, since under natural conditions, incompletely saturated permeable sandy layers are often encountered, especially in near-surface zones that are important for the founding of engineering structures.

Studies conducted on partially saturated samples subjected to triaxial monotonic and cyclic loads indicate clearly that liquefaction susceptibility decreases with decreasing saturation of soil pores.

In the case of monotonic load, excess pore pressure is generated regardless of the saturation level. However, the higher the saturation, the higher the pressure generated. At the saturation level corresponding to Skempton's coefficient greater than 0.5, non-cohesive soil subjected to monotonic triaxial compression liquefied. For lower saturation, the soil response was similar to that characteristic of drained conditions. Another characteristic feature is that the maximum and residual deviatoric stress increase as Skempton's coefficient decreases.It should be noted that practically for the whole range of saturation, the maximum values of the deviator were achieved before reaching the Coulomb-Mohr yield surface. Moreover, the results of the tests show that the instability line determined by the position of the maximum stress deviator in the effective stress space is not straight, but strongly curved.

In samples subjected to cyclic triaxial compression, the effect of saturation on liquefaction was even more evident. The samples liquefied only for the $B$ coefficient values greater than 0.95. At lower saturation levels, excess pore pressure was generated, but liquefaction did not occur despite the large number of load cycles. A similar trend was observed in monotonic studies, in which the value of excess pore pressure depended on the saturation level.

Moreover, the effect of saturation on the pressure wave propagation velocity was studied, which is of great practical importance in assessing the location of fully and partially saturated zones. Tests carried out in a triaxial apparatus equipped with piezoelectric sensors indicate a clear relationship between the saturation level and the P-wave propagation velocity. For small $B$ values, these velocities were of the order of $800 \mathrm{~m} / \mathrm{s}$, whereas for nearly full saturation they reached about $1200 \mathrm{~m} / \mathrm{s}$.

As the analysis of the results has led to many interesting conclusions, it seems appropriate to confirm them by further research and to extend these studies to other types of non-cohesive soils, including those with a significantly higher content of the fine fraction.

\section{References}

Castro G. (1975) Liquefaction and cyclic mobility of saturated sands, J. Geotech. Eng. ASCE, 101 (GT6), 551-569.

Been K., Jefferies M. G. (1985) A state parameter for sands, Géotechnique, 35 (2), 99-112. 
Ishihara K. (1998) Liquefaction and flow failure during earthquakes, Géotechnique, 43 (1), 351-415.

Lipiński M. J. (2000) Undrained Response of Cohesionless Soils to Monotonic Loadings, Ph.D thesis, Technical University of Gdańsk.

Lipiński M. J. (2013) Criteria for determination of geotechnical parameters, SGGW publishing, Warsaw (in Polish).

Mierczyński J. (2008) Experimental investigations of steady state properties of soil, IBW PAN internal report (in Polish).

PIANC (2001) Seismic Design Guidelines for Port Structures, Lisse/Abingdon/Exton(Pa)/Tokyo, Balkema.

Poulos S. J. (1981) The steady state of deformation, J. Geotech. Eng. ASCE, 107 (GT5), 501-516.

Skempton A. W. (1954) The pore pressure coefficients A and B, Géotechnique, 4, 143-147.

Świdziński W. (2005) Evaluation of liquefaction susceptibility of a subsoil, Inżynieria Morska $i$ Geotechnika, 26 (2), 65-73 (in Polish).

Świdziński W. (2006) Mechanisms of compaction and liquefaction of non-cohesive soils, IBW PAN (in Polish).

Świdziński W. (2011) Instability of post-flotation tailing ponds due to static liquefaction, IBW PAN internal report (in Polish).

Świdziński W. (2013) Safety assesment of the TSF Żelazny Most, Report for 2012, commissioned by O/ZH KGHM POLSKA MIEDŹ S.A. (in Polish).

Świdziński W., Mierczyński J. (2003) Determination of steady state line for sands, Inżynieria Morska $i$ Geotechnika, 24 (3/4), 194-199 (in Polish).

Świdziński W., Mierczyński J. (2005) Instability line as a basic characteristic of non-cohesive soils, Arch. of Hydro-Engineering and Environ. Mech., 52 (1), 59-85.

Świdziński W., Mierczyński J. (2010) Investigations of elastic response of non-cohesive soils by seismic waves, Wydawnictwo Techniczne Politechniki Krakowskiej, 1-Ś, Issue 16, Year 107, 63-82 (in Polish).

Świdziński W., Mierczyński J. (2015) Response of saturated post-flotation tailings subjected to cyclic loading in undrained conditions, Inżynieria Morska i Geotechnika, 36 (3), 466-473 (in Polish).

Świdziński W., Tschuschke W., Świerczyński W., Wolski W. (2015) Mining Wastes Utilisation Object “Żelazny Most” - significant geotechnical challenge, Inżynieria Morska i Geotechnika, 36 (3), 186-193 (in Polish). 